\title{
PRIMEIRO OS AMIGOS: OS ANIVERSÁRIOS DA INFÂNCIA, DAR E RECEBER*
}

\author{
RÉGINe SiRotA** \\ "Um dia extraordinário" \\ Durante um dia inteiro, \\ é meu aniversário. \\ Tenho o direito de tudo fazer, \\ como no ano passado. \\ Comer sorvete de café \\ no café da manhã, \\ levar pães de passas \\ na escola para meus amigos, \\ pedir à professora para que toque \\ minha fita favorita \\ e ir deitar muito mais tarde \\ que nas outras noites, \\ depois de ter partilhado meu bolo \\ e aberto todos os meus presentes.
}

(Corinne Albaut, Cantigas para meu aniversário, 1998) ${ }^{1}$

\begin{abstract}
RESUMO: Desde a infância, os aniversários propiciam trabalhos de socialização. Esse ritual, que costuma agrupar crianças da mesma faixa etária, faz surgir uma obrigação de trocar presentes: dádivas e contradádivas regem as seqüências da festa de aniversário. A abordagem etnográfica permite apreender o papel que cada ator social (filhos, pais, amigos) desempenha na construção social desse ritual. Os presentes estão no cerne de um verdadeiro trabalho de negociações no qual se confrontam constantemente normas e valores.
\end{abstract}

Palavras-chave: Aniversário. Ritual. Dádiva. Contradádivas. Infância. Socialização.

* (C) pUf 1998. Uma outra versão deste texto já foi publicada em: Ethnologie française, Paris: PUF, XXVIII, 1998, 4, Les cadeaux: à quel prix?

Tradução de Alain François, com revisão técnica de Ivany Pino.

** Professora da Universidade Paris V, Instituto Nacional de Pesquisa Pedagógica (INRP). E-mail: sirota@inrp.fr 
FRIENDS FIRST: CHILDHOOD BIRTHDAYS, GIVING AND RECEIVING

ABSTRACT: Ever since childhood birthday parties allow a process of socialization. Such ritual, which usually gathers children of a same age group, is an opportunity to exchange presents: gifts and counter-gifts structure the sequences of birthday parties. An ethnological approach thus enables to seize the contribution of each social actor (children, parents, relatives, and friends) in the social constructions of this ritual. Presents are the object of a real negotiation implying a permanent confrontation of norms and values through which a social link is built.

Key words: Birthday. Ritual. Gift. Counter-gift. Childhood. Socialization.

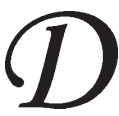

urante a infância, desejar um feliz aniversário marca-se essencialmente por um presente. Aqui, onde o aniversário é analisado como um ritual de socialização, consideraremos os presentes como objetos que participam dessa socialização em termos de celebração do indivíduo, de modelagem da identidade e de construção do vínculo social. ${ }^{2}$

\section{Um imperativo categórico do aniversário, o presente}

Por meio da trajetória do objeto que, segundo o esquema de Mauss (1950), percorre as três obrigações dar-receber-devolver, indo da compra à oferta até o agradecimento, a construção social do presente de aniversário permite apreender um certo número de princípios que regem o que está em jogo num presente, nessa situação específica do processo de socialização. Podem-se aqui recortar duas cenas: o momento da compra, o momento da oferta. A primeira permite apreender os critérios de escolha tais como se constroem na situação individual e entender como se configura o que está em jogo, situação complexa, na qual pais, filhos e sociedade comercial estão interagindo. Em compensação, as modalidades da oferta, por um lado, e a análise do estoque de presentes recebidos por uma criança, por outro, fazem surgir a resultante dessas negociaçóes e os modos de socialização que delas decorrem.

Pois a criança aprende a receber e a oferecer ao mesmo tempo: se no círculo familiar, o presente recebido precede, durante alguns anos, a oferenda de presentes, uma vez que a regra, ${ }^{3}$ rigorosamente desigualitária, não comporta reciprocidade na pequena infância, em contrapartida, no 
círculo de sociabilidade entre amigos, característico da infância contemporânea, o qual se inicia muito cedo, entre 2 e 3 anos, a oferta do presente vem imediatamente. Trata-se de um aprendizado conjunto e precoce das regras de civilidade modernas, tanto para as crianças como para os pais, que vão logo ter de enfrentar esse novo ritual. Pois ao ritual do aniversário familiar veio se somar, já há uns 15 anos, o aniversário "amigal", , festa de crianças reunindo o círculo social do "impetrante". Assim, tanto os presentes de aniversário recebidos no primeiro como os trocados no segundo, infinitamente mais freqüentes, marcam ao mesmo tempo a constituição do círculo social e a construção de regras de civilidade: em outras palavras, a aprendizagem da implementação do vínculo social por meio da dádiva. É, portanto, principalmente aos presentes trocados quando desse aniversário "amigal" que este artigo se interessará."

\section{Escolher, uma negociação, reflete a mudança de lugar da criança}

Cena flagrada numa loja de brinquedos, numa tarde de sábado: um pai com seus dois filhos, Joachim (10 anos, aproximadamente) e Nicolas (5 anos):

"Pronto, vamos à seção dos meninos. Um dragão, tá..., não é muito espetacular, mas pode servir de presente de aniversário; espera, vou chamar a mamãe para saber o que ela acha", disse o pai.

Ele liga: "Qual o orçamento? Sim, estou nos brinquedos da Fisher Price com as crianças. Joachim quer que eu compre um dragão, mas tem um carrinho ou um caminhão de bombeiros muito mais vistosos; ele tem o quê, quatrocinco anos? Você acha que vai gostar? Ele vai ficar feliz?”.

(...)

- "Não, se ele não tem o resto do jogo, não tem graça. Então, vai o dragão", disse Nicolas.

(...)

- "Não, Nicolas, é caro demais, e um castelo não tem nada a ver, isto é o tipo de presente que a família compra, você vai deixá-los constrangidos, eles não vão gostar, são os pais que dão isto", disse o pai.

Essa cena banal reúne os principais elementos da negociação envolvida na compra de um presente para um aniversário "amigal”. Nela está enunciada grande parte dos critérios de escolha do presente: identidade de gênero, peso financeiro, estratégia de representação e de dis- 
tinção, critério de idade, princípios culturais, enunciação e aprendizado das regras de civilidade e instauração de uma hierarquia de valores. Isso, num espaço de negociação que deixa uma certa margem à autonomia da criança e nos permite perceber a mudança do lugar da criança na família. Com efeito, nesse caso, como vimos, depois de consultar todos os membros da família, a mãe - chamada para ajudar pelo celular, pois ela costuma gerenciar essas compras - e o irmão mais velho, o qual, com 10 anos, já tem experiências desse tipo de situação, o pai acabará decidindo em favor da primeira escolha de seu filho menor. Essa autonomia decorre quer de princípios educativos claramente afirmados pelos pais, quer de um certo "realismo". Assim a mãe de Adrien, a qual, para ganhar tempo, comprava sozinha os presentes quando este era pequenino - isto é, até os 3 anos -, enfrentou a situação seguinte: seu filho recusava-se terminantemente a oferecer o jogo que ela escolhera, pois em nada correspondia com o que ele queria oferecer. Desde então, ela passou a comprar os presentes sempre com ele e a respeitar de fato suas escolhas. Estas costumam resultar de negociações prévias entre pares, no pátio da escola; Tom (7 anos), por exemplo, combinou com seus amigos para receber o que desejava: um Marsupilami* de pelúcia, uns Batman e um livro contando a lenda dos Cavaleiros da Távola Redonda, que um deles já tinha.

Portanto, normas de crianças e normas de adultos entram em competição. Às vezes, as concepções do grupo de pares das crianças predominam: "A uma menina, a gente dá uma Barbie, a um menino, uns Batman ou uns Power Ranger", e os pais abdicam diante da argumentação da criança: "Foi o que o Pierre pediu", embora isso contrarie todas as suas estratégias culturais. Nesse caso, são as normas do grupo de idade, geralmente fortemente influenciadas pelos seriados e as campanhas de propaganda, que determinam a compra, coisa pela qual aquele dos pais que acompanha a criança costuma se desculpar: "Não pude fazer nada". Ou, então, impõe-se o que encarna a passagem para uma nova faixa etária: "Ela quer maquiagem de verdade, com batom de verdade, não um negócio de criança".

As mães também podem negociar ao confirmarem a presença de seu filho ou filha. Elas se informam a respeito dos gostos de quem

N. do T.: Personagem de história em quadrinho (HQ) criado por André Franquin. Segundo o jornal Spirou (que publicava suas histórias), o Marsupilami é anfíbio, onívoro e fala de vez em quando. É um mamífero que bota ovos. 
convida, pois, às vezes, não o(a) conhecem. Muitos presentes de aniversário, sobretudo quando as crianças são muito pequenas, são comprados por pais que nunca viram o(a) aniversariante, que apenas seu filho ou sua filha conhece. Essas mães conversam entre si quando têm uma certa intimidade, o que permite avaliar o investimento financeiro potencial: "Ele está louco por um kit Catapulta e Trabucos", ou passam então um critério moral e prático preciso: "Não muito grande, nem muito espaçoso". No grupo de pares dos pais também ocorre avaliação e aprendizado das novas normas sociais dessa festa de aniversário:

"No início, comprava presentinhos entre 20 e $30 \mathrm{~F}^{6}$ nas Paris Pas Cher, ${ }^{7}$ mas logo entendi que não era assim e passei a comprar verdadeiros presentes". Em sentido inverso, diante da freqüência inesperada dos convites, algumas mães decidem moderar-se na escolha dos presentes e, conseqüentemente, no valor das compras.

Portanto, a compra encontra-se no cerne de uma negociação com parâmetros complexos, quando não contraditórios. Mesmo podendo haver negociação entre as crianças, o(a) aniversariante nunca tem certeza de que o outro poderá comprar o objeto de seus desejos uma vez que essa negociação é dupla: entre as crianças e entre uma delas e aquele dos pais que vai comprar. Os critérios de compra do presente, que as crianças formulam precocemente, já aos 3 anos de idade, são: "agradar", "ser bonito", "ser uma surpresa". Eles podem rapidamente se tornar difíceis de respeitar.

Os princípios dos pais, que refletem o estilo educativo da família, traduzem-se não somente no tipo de presente escolhido, como também na negociação financeira. Poucas mães deixam total liberdade de escolha aos filhos: elas costumam fixar limites financeiros que variam geralmente em função do grau de amizade entre as crianças. É assim que se constitui uma das regras do aniversário: "Para grandes amigos, presentóes; para pequenos amigos, presentinhos". De fato, o preço dos presentes comprados marca geralmente como um sociograma o grau de amizade que liga as crianças entre elas ou a proximidade das famílias. Pois a autonomia da criança na constituição de sua rede social está em jogo, e a compra do presente representa a primeira resposta a um convite oriundo de um círculo social sobre o qual, não raro, os pais têm apenas um domínio limitado. Estes, entretanto, costumam favorecer essa sociabilidade infantil por dois lados: ao consentirem com essa ampliação do círculo social, e ao aceitarem, ou pelo menos negociarem, as normas culturais do presente. 
Com efeito, as normas dos pais e as das crianças estão envolvidas, tanto em termos de gerações como de grupos de pares, na "co-construção" desse ritual. Se, no exemplo acima, o valor financeiro do presente escolhido correspondia às normas de civilidade dos pais - para tal vínculo social, tal tipo de presente -, a escolha cultural, por sua vez, correspondeu aos valores do grupo de crianças.

Normas que devem ser aplicadas sutilmente: a mãe de Hélène, quando levou sua filha à festa, tentou explicar discretamente que aquela máquina fotográfica estava em oferta, para justificar um presente que lhe parece importante demais, mas que ela desejava consolidar e significar a importância do vínculo entre as duas crianças.

Em virtude das limitações financeiras, há também um aprendizado da negociação dos valores e das limitações entre a oferta comercial, os pais e as crianças, quando da compra. Logo, não se pode raciocinar apenas em termos simbólicos, pois os presentes de aniversário apóiam-se em e são suscitados por uma dinâmica econômica, que "propóe" objetos de consumo suscetíveis de se tornarem presentes de aniversário ou que foram até especialmente concebidos para tanto. ${ }^{8}$

O objeto selecionado será então cuidadosamente embrulhado, geralmente na loja, para adquirir definitivamente seu estatuto de presente e tomar o caminho da casa do(da) aniversariante.

Oferecer e receber, ou a aprendizagem das regras de civilidade

A cena da oferta reveste-se de duas formas principais. Quer os presentes sejam abertos à medida que os convidados chegam, quer sejam guardados e abertos um após o outro mais tarde. Entretanto, há sempre oferta e apreciação da oferta, ao mesmo tempo, durante uma fase de exposição mais ou menos bem ordenada, na qual os presentes são exibidos, apreciados, avaliados tanto pelo donatário e seus pais, quando este é pequeno, como pelo conjunto dos amigos.

$\mathrm{Na}$ casa de Kevin, Aurélien, como o resto dos convidados, oferece o presente que segura diante de si assim que a porta se abre, o que parece ser o "Sésamo" da participação ao aniversário. O presente é aberto imediatamente. Em compensação, na casa de Florence ou na de Justine os presentes são cuidadosamente guardados na chegada de cada convidado. O protocolo é o fruto de uma soma de experiências desastradas, segundo 
as mães, nas quais muitos presentes abertos imediatamente acabaram abandonados no chão e rapidamente quebrados. A mãe de Justine espera até as últimas crianças chegarem e escolhe um momento estratégico no "andamento do aniversário", geralmente bastante cedo, o qual costuma marcar a abertura das festividades, antes dos jogos (embora às vezes fique para depois do espetáculo). Ela junta as crianças, manda-as se sentarem em círculo no carpete no meio da sala, ou perto da mesa do bufê. Uma vez o círculo pronto, chega um dos pontos altos do aniversário. Todos os presentes em seus embrulhos estão expostos no centro do círculo, diante de Justine. Esta vai pegar cada um, perguntar quem o trouxe, abri-lo, mostrá-lo a todos e agradecer de modo mais ou menos espontâneo. Pois há nisso uma apreciação pessoal e coletiva, o que permite justamente a elaboração das normas do grupo e sua interiorização. Às vezes, a criança deve agradecer antes de abrir, pois se trata de aprender a agradecer o gesto da dádiva e não especificamente o objeto oferecido e, numa idade em que as regras de polidez ainda não foram integradas, o risco de gafe é grande. Isso justifica a necessidade e a regra do embrulho: o momento dos agradecimentos e da avaliação coletiva é um momento delicado de aprendizado das regras de polidez e de civilidade, quando o brinquedo não agrada, por exemplo, ou quando a criança já tem um igual. Marcella, 2 anos, vai abrir os seus nos braços de sua mãe. Florence, 7 anos, os abrirá sob o olhar muito vigilante da sua. Quanto à Rachel, 10 anos, promovida a mestre-de-cerimônias, ela abrirá sozinha o conjunto de presentes em meio ao gentil burburinho de seus amigos.

Entretanto, independentemente do processo escolhido, as mães, pois são sempre elas que oficiam naquele momento, estão muito presentes, num modo discreto ou fortemente instigante: "Ó, que lindo", "Este é demais", "Que ótima idéia", "Diga obrigado a Marianne”. Elas acrescentam exclamações quando julgam que faltam, dissimulam as decepçóes que, às vezes, exprimem-se muito diretamente: "Isto não é presente de aniversário", "Xiii! Já tenho um igual”, e comentam o interesse do presente. Às vezes, ocorre uma verdadeira explicação do texto da cena em jogo, a fim de não deixar a situação se deteriorar, quando o presente não suscita o menor interesse do donatário. De fato, ao mesmo tempo em que impóem um ritual de polidez, elas ensinam incitando ao controle das emoções, quer se trate de reprimir ou dissimular sua decepção, quer de exprimir o prazer e a alegria. Como os agradecimentos vêm durante ou logo após a cena da abertura, quanto mais jovem a criança, mais difi- 
cilmente ela se conterá, pois é preciso paciência para não arrancar os papéis dos embrulhos de uma vez e abri-los corretamente. Uma vez os presentes abertos, eles são juntados a distância, no salão, no sofá, numa mesa, ou ainda no quarto da criança. Tal como a exposição dos presentes de casamento, o troféu de aniversário é exibido.

\section{O troféu do aniversário, ou a constituição da identidade}

Esse troféu representa um parque ou um estoque de presentes cuja análise permite apreender a resultante das múltiplas negociações que o precederam, deixando transparecer um processo de socialização em plena constituição, pois por meio desse estoque se estabilizam e exprimem normas e valores da infância contemporânea.

Se compararmos os estoques respectivos recebidos nas festas desses quase 50 aniversários, surgem alguns princípios de fabricação do troféu: por um lado, a instituição do círculo social, por outro, a celebração do indivíduo na dupla consagração de sua individualidade e de seu pertencimento ao grupo de pares.

De fato, a análise da lista dos doadores permite acompanhar a evolução do círculo social infantil e os graus de proximidade. O número de convidados e, portanto, de presentes gira em torno de dez (os pais costumam limitar a lista de convidados a esse número). Ao círculo de família dos primeiros anos vêm acrescentar-se, a partir dos 3 anos, os primeiros amigos, que se somam aos primos e filhos dos amigos dos pais, da mesma geração. Em seguida, no decorrer da escolaridade, vão se suceder os amigos da creche, da escola maternal ou os vizinhos, com os quais os pais constituíram relaçóes de ajuda mútua e amizade, para acabar se concentrando nos colegas da turma. Uma vez que a escola primária e, em seguida, o colégio estruturam principalmente a rede de sociabilidade, o convite para o aniversário ratifica o pertencimento a essa rede, e a importância ou a personalização do presente significa o grau de proximidade.

A personalização dos presentes depende muito do nível de proximidade e de intimidade; quanto mais próximo o amigo, mais o presente levará em conta seus gostos. No âmbito das negociações citadas anteriormente, as crianças decodificam isso com delicadeza: "Ele toma o maior cuidado com o que oferece", "Que presente mais sem graça”, "Ela sempre me oferece algo superbonito". Assim, às vezes, alguns presentes se 


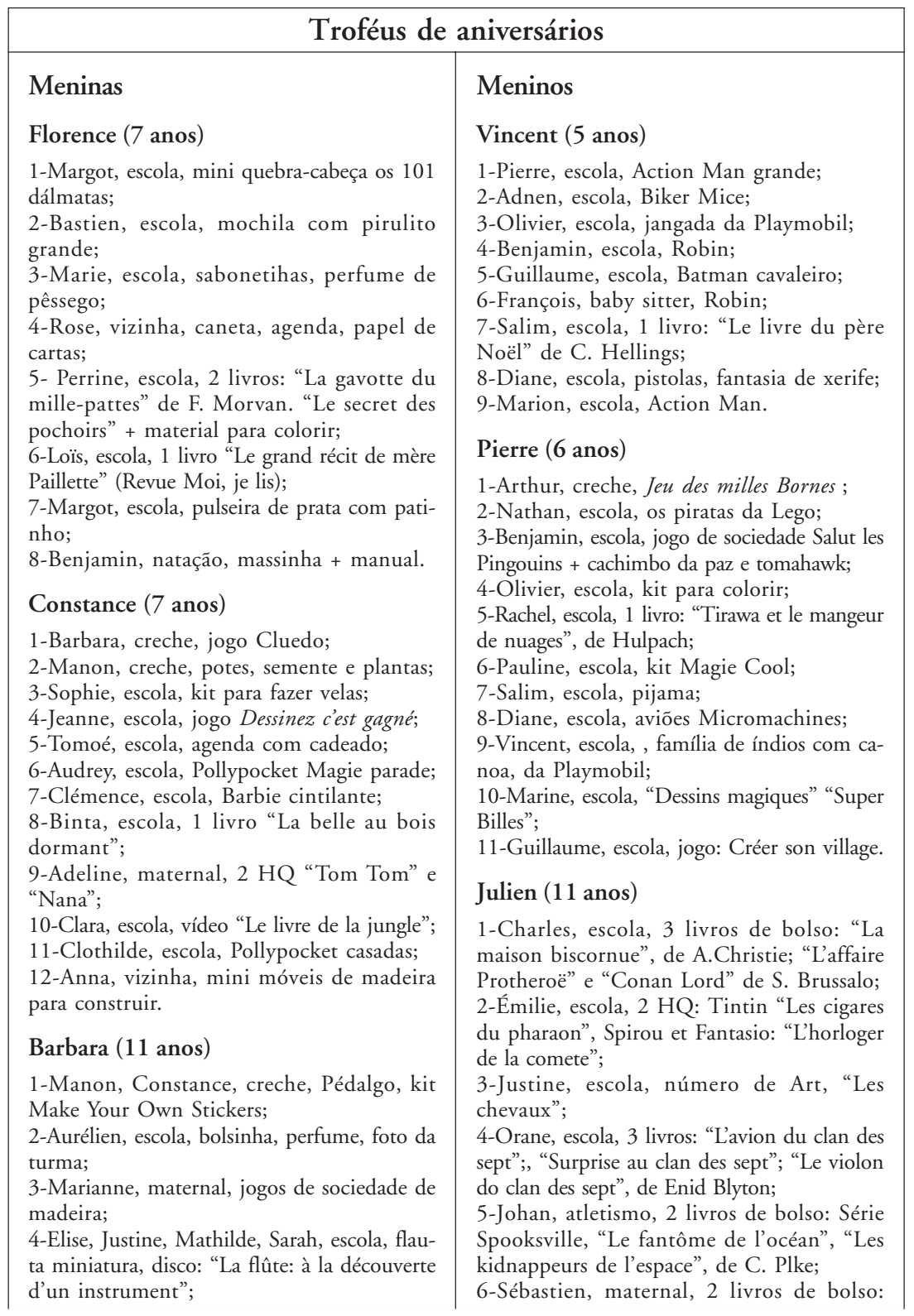


5-E1 Mafoud, escola, Tio Patinhas gigante + pequeno 11 anos de papeláo;

6-Anthony, escola, kit espuma de banho, sabonete de morango, 2 esponjas;

7-Hadrien, escola, 1 livro "L’abécédaire de l'impressionnisme";

8-Anna, vizinha, 2 CDs Spice Girls, Hansum; 9-Caroline, 2 livros de bolso: série L'instit: "Aimer par cœur" Série Chair de poule : "leçons de piano et pièges mortels", de R.L. Stine;

10- Julien, escola, livro: "Agates et calots". de Joffo;

11-Marc, escola, bijuteria, pequena dançarina de prata;

12-Paul, escola, caneta de madeira com estojo de madeira;

13-Laëtitia, escola, 1 livro de bolso: "Alice et le secret du parchemin" de C. Quine, chaveiro ursinho;

14- Clément, escola, 2 livros de bolso "J'ai tant de choses à te dire", de J. Marsden, "La terre de Yenn", de J. Coué ;

15-Aurélien, 2 livros de bolso: Série cœur grenadine: "La fille sur le plongeoir" de J. Quin "Harguin, Histoire à se cacher sous le lit", de A. Hitchcock;

16-Arthur, escola, 2 livros de bolso: "Les Aventures de Sherlock Holmes", de A. Conan Doyle;

18-Wassil, escola, espuma de banho, pequeno perfume;

19-Pierre, amigo do irmão, espelho argentino.
"Charlie et le grand ascenseur de verre", de R. Dahl; "Alice de Barra", de P. Thies;

7-Adèle maternal, 2 livros de bolso: "Vallée fantôme, nuit noire", de L. Beach; "Désirs dangereux", de R.L. Sterne, Série Chair de poule;

8-Barbara, escola, 2 livros: "Le deuxième livre d'anticoloriage"; "Les secrets de la boussole" (coll. "Les secrets");

9-Romaïn, filho de amigos, camisa Creeks; 10-Marc, escola, T-shirt preto da Nike;

Este quadro dos troféus mostra o número de convidados, e, em ordem, o nome da criança, a origem do vínculo social (escola, creche, natação etc.) e o tipo de presente oferecido.

distinguem nitidamente por sua especificidade e seu preço. As melhores amigas da Barbara fizeram uma vaquinha para lhe oferecer uma flauta transversal miniatura, pois ela ficara fascinada por um violoncelo miniatura na casa de uma amiga. A mãe de uma delas atravessou Paris de lado a lado para encontrar o objeto desejado, pois aqui tudo convergiu: conhecimento íntimo dos gostos e individualização do presente (Barbara toca flauta), surpreender (fizeram uma vaquinha discreta para juntar a soma necessária), agradar (elas notaram o fascínio de Barbara) e estratégia cultural parental - em termos de distinção e de educação (a 
mãe em questão toca numa orquestra clássica amadora). Em sentido oposto, presentes fortemente estereotipados permitem realizar o rito social num certo anonimato. É o caso, às vezes, das bonecas Barbie, que podem ser tanto o resultado de uma batalha ferrenha contra os pais, e portanto uma escolha explícita da criança, quanto um presente para qualquer oportunidade: "É menina? Então vai uma Barbie". Do mesmo modo, o número de livros oferecidos perto do fim do primário, com o ingresso na adolescência, não reflete realmente uma propensão particular para a leitura, que poderia parecer contradizer as estatísticas francesas sobre os jovens e a leitura (Singly, 1993).

"Gosto de presentes que têm um sentido, que agradam mesmo. Nunca
leio os livros, só se eu mesma escolhesse. Se a Manon e a Constance me
dão um livro, é que já passaram por todas as lojas. Os livros, depende
dos gostos; para a Mathilde e a Elise, é realmente um presente, mas o
Clément não vai achar nada demais. Um livro, acho legal, mas não deve
ter apenas livros, um livro não é caro, não é difícil de encontrar".
(Barbara)

Pois, às vezes, a proporção de livros é extremamente surpreendente. Assim, para sua primeira festa dançante, quando completou 11 anos, Julien recebeu 16 livros, pois algumas crianças ofereceram dois ou três livros. Qual o sentido desse presente? Primeiro, um livro é fácil de se comprar e tem um preço relativamente moderado, o que permite moderar os gastos. Pode-se, entretanto, notar que esses livros, que fazem parte das coleções de bolso, são geralmente oferecidos por dois ou três, como se o presente devesse alcançar uma certa soma e um volume mínimos, e não bastasse, em si, pelo seu conteúdo. Algumas crianças temem tais presentes e, constatando que, a partir de uma certa idade, "Quando a gente sabe ler, só ganha livros", elas sentem saudades do tempo dos brinquedos. Esse deslocamento ocorre paralelamente à aprendizagem da leitura, e passa da história em quadrinhos ao livro de bolso, desdenhando os lindos livros clássicos em favor de uma literatura infanto-juvenil recente, com a influência das modas, no caso para os romances policiais especialmente destinados às crianças. Mas, em contrapartida, um livro pode ser um presente escolhido muito precisamente: assim Julien ofereceu Agates e calots, de Joffo, que pagou com parte de sua mesada, a Bárbara, pois "adorei Um sac de billes que acabo de ler, e tenho certeza de que ela vai gostar". 
A identidade de gênero parece um fator particularmente importante na constituição do estoque. "Obviamente, o assunto é irritante, sobretudo para as mulheres, mas não é novo", como afirmou Simone de Beauvoir (1949) nas primeiras linhas de O segundo sexo. Tanto que neste ela parece quase caricatural, pois repete, demonstra e reproduz de maneira totalmente estereotipada a construção da identidade. $\mathrm{O}$ que parece estar basicamente em jogo é a afirmação do pertencimento ao grupo de pares e de gênero, durante este ritual que convoca o grupo para a celebração de um de seus pares. Uma simples leitura do quadro dos troféus, confirmada pela análise dos quase 500 presentes oferecidos nesses quase 50 aniversários, deixa transparecer que os presentes são fortemente "sexuados", sobretudo em torno dos 5/7 anos, característica que se atenua com o ingresso no colégio. De fato, boa parte dos presentes é oferecida em função do sexo, de maneira exclusiva: do lado da "fabricação dos machos" (Falconnet \& Lefaucheur, 1975), as personagens guerreiras dos seriados de televisão ou dos filmes de ciência/ ficção, como Batman, os Power Ranger, o Homem Aranha, Robocop, Action Man, Biker Mice, Dragon Ball Z ou as Tartarugas Ninja, ocupam um lugar importante com seu exército de bólidos supersônicos, armas ou bases espaciais, aos quais se acrescentam heróis da Antiguidade reciclados pelos Estúdios Disney, como Hércules ou Zeus. Esses "bonecos de ação" convivem com aventureiros mais clássicos como piratas, índios, caubóis, cavaleiros e médicos da Playmobil ou da Lego. Do "lado das meninas" (Belloti, 1973), 20 anos depois, reencontramos o pólo diametralmente oposto desses estereótipos, com a Barbie e seus acessórios, os cenários das Pollypocket e alguns Playmobil, como a carroça de noiva. Desse lado, entretanto, os presentes são um pouco mais variados, embora reflitam e estruturem muito fielmente os estereótipos da identidade feminina: o charme, com jóias, bolsas, produtos de beleza e lindos adereços, ou então a introspecção e a clausura sobre si mesmas por meio de ferramentas de escrita domésticas comuns9 (Albert, 1993), como papel de cartas, canetas, agendas, álbuns de fotos e carnets secrets (diários com cadeados). Os presentes de material escolar (estojos, réguas) só aparecem em aniversários de moças, ratificando sua seriedade na escola. Observamos apenas uma infração a esse código: Caroline, apaixonada pelas Tartarugas Ninja, pediu uma a uma amiga, e seu pai ficou se desculpando, aflito, por este gosto masculino de sua filha. 
Em compensação, embora alguns jogos de sociedade sejam oferecidos dos dois lados, como o Mille bornes ou o Mini-Bac, ${ }^{*}$ eles são muito mais freqüentes para as moças, assim como os kits de trabalhos manuais, ferramentas de jardinagem e kits para fazer velas. Fora desses arquétipos, algumas histórias em quadrinhos, como Tintim, Boule et Bill, Marsupilami, e livros científicos são oferecidos indiscriminadamente dos dois lados, além de CDs de bandas da moda e fitas de vídeo.

Vê-se claramente, aqui, como se transmitem e difundem, tanto entre gerações como dentro de uma mesma geração, os elementos identitários por meio dessa construção do estoque de presentes que, ano após ano, pela repetição desse ritual coletivo contribui à formação do espaço físico e mental da vida privada de cada criança; esse processo de socialização opera independentemente da posição da criança, quer ela seja, segundo o momento do ciclo, doadora ou donatária.

Contudo, os presentes que os convidados trazem não são os únicos objetos trocados quando do aniversário "amigal".

\section{Os contrapresentes ou a "generosidade dos pequenos"}

De aparição recente, a distribuição de presentinhos que podem ser considerados contrapresentes faz parte de quase todo aniversário. Eles, que também são quase obrigatórios, devem ter um valor nitidamente inferior ao presente ou, pelo menos, assim parecer. Essa desigualdade marca claramente a dinâmica de troca na qual se inscreve o aniversário: se o contrapresente há de ser assimétrico, é porque apenas representa um contrapresente "instantâneo", acompanhado por balas ou doces. Os contrapresentes lembram muito o arroz jogado ou os docinhos distribuídos no momento do batismo, para fazer aceitar a criança pela faixa etária que a acolhe (Zonabend, 1980). Por sinal, essa prodigalidade de doces acompanha o aniversário durante toda a tarde. Reencontramos aqui a imagem antiga da generosidade que Starobinski (1994) lembrou: "Ao dispersar a riqueza, eles chamam sobre si a bênção dos deuses e um novo afluxo de riqueza. Eles se atribuem o domínio de uma superabundância que vai gerar uma nova abundância”. Pois, exatamente como o cavaleiro de Duby

N. do T.: Mille bornes: Jogo com um baralho especial que representa uma espécie corrida de mil milhas. Mini Bac: Jogo de perguntas e respostas, de tipo Quiz. 
que Starobinski cita, aquele cujo aniversário se celebra "há de nada guardar em suas mãos. Tudo o que lhe chega, ele dá. De sua generosidade, ele tira sua força e a maior parte de seu poder ou, pelo menos, sua fama e a viva amizade que o cerca".

Do mesmo modo, os contrapresentes são parcialmente destinados a compensar a frustração sentida pelas crianças diante do amontoamento de presentes recebidos pelo "aniversarioso". ${ }^{10}$

"O presentinho é um negócio que você pode guardar, quando a gente vai a um aniversário em algum lugar e aquele que convidou ganhou um monte de presentes. Isso agrada, a gente gosta de ganhar. Quando alguém vai embora, gostaria de levar uma lembrancinha. Quando a gente é pequena, um negócio maior, quando a gente é maior, um negócio menor, igual para todo mundo. É sempre legal, num embrulho bonito, se não tem embrulho, é menos um presente, a gente sente menos prazer ao abri-los, descobri-los, recebê-los. Legal mesmo é criar uma atividade para recebê-los, como quando a gente era pequena, mas a gente já passou da idade de brincar de pescaria". (Justine)

$\mathrm{O}$ verdadeiro contrapresente, que vai se inscrever no círculo da troca, será o presente cuja criança que acaba de oferecer um receberá quando, por sua vez, vai fazer o seu aniversário. O jogo da dívida e da troca se completará apenas naquele momento. O princípio da dívida mantém o círculo da troca. Por isso, obviamente, a dádiva não pode ser devolvida imediatamente, motivo pelo qual o contrapresente, mesmo se está quase sempre embrulhado como um presente, pode conter tanto um brinquedo como doces ou ser acompanhado por balas. Entretanto, para as crianças, hoje em dia, ele praticamente virou uma obrigação; e nas raríssimas vezes em que não houve, elas estranharam o fato em alto e bom som.

Ao troféu do "aniversarioso" corresponde então o ganho dos convidados, constituído pelo contrapresente, as balas e eventualmente os prêmios ganhos em brincadeiras.

O ganho

Os contrapresentes têm suas próprias regras, destinadas a atribuir o estatuto de contrapresentes a objetos concebidos como tais pelo comércio, ou seja, geralmente comprados ou fabricados com este fim: 
- Os contrapresentes devem ter um valor ou um volume inferiores aos dos presentes; na casa da Aurélia, as crianças ficaram constrangidas diante do contrapresente, um porta-lápis e uma caderneta bastante imponentes, pois o conjunto representava um volume praticamente tão grande quanto aquele que elas mesmas haviam levado.

- Deve haver tantos contrapresentes quanto crianças presentes; inclusive, o aniversariante, que já ganhou muitos presentes, também recebe um. Do mesmo modo, se uma irmãzinha ou um irmãozinho foi "convidado" na última hora, deve receber um contrapresente. Nesse caso, as mães prevêem ou improvisam um presente. Os irmãos e as irmãs dos convidados que têm idade adequada também recebem um. Toda criança que participa da festa tem direito a um contrapresente.

- Os contrapresentes devem ser embrulhados como verdadeiros presentes. Embora o comércio proponha embrulhos especiais vendidos em pacotes de seis ou dez, eles costumam ser "bricolados" pelas mães, em papel crepom, ou decorado, em papel com estrelas, por exemplo, para um aniversário cujo tema é Guerra nas Estrelas, ou em simples papel-jornal. Esse embrulho deve ter uma relação de coerência para atribuir a qualidade de contrapresente a conjuntos mais ou menos homogêneos de objetos. As vezes, o embrulho é reduzido ao mínimo, sobretudo quando as mães querem marcar sua distância dessa obrigação de prodigalidade. Então, pode ser um copinho cheio de balas, um simples saco para congelar, ou uma bolsa de plástico do comércio, pois a criança convidada deve ter como levar o conjunto de ganhos eventuais que obteve; essa bolsa contém geralmente não apenas o contrapresente, mas balas previstas para este fim e, às vezes, os prêmios ganhos quando das brincadeiras.

- Os contrapresentes são o objeto de uma encenação, de uma apresentação que pode revestir formas diferentes: quando as crianças são muito pequenas, os contrapresentes são obtidos por meio de jogos, o mais comum sendo o da pescaria, no qual cada criança resgata um presente com uma vara geralmente "bricolada” em casa. À medida que crescem, a pescaria desaparece, pois ela encarna a festa de aniversário dos pequenininhos. $\mathrm{O}$ contrapresente é então distribuído no final do aniversário, quan- 
do da saída, quer pelo aniversariante ou por sua mãe. Aprontados de antemão, à espera, os contrapresentes costumam ser apresentados numa cesta, numa fruteira, numa bandeja, exibida em cima de um móvel, quer na cozinha ou num canto da sala de estar, como promessa potencial. Ou então eles surgem de modo espetacular no final. Cada criança está certa de receber um, a tal ponto que, se uma tiver de ir embora mais cedo, a mãe anfitriã antecipa-se para lhe entregar um ou, às vezes, manda-o no dia seguinte. Mais tarde, com a adolescência e o surgimento das festas dançantes, na idade do colégio ou no fim do primário, o tempo dos presentinhos desaparece, objeto de sorrisos constrangidos e nostálgicos dos maiores.

- Os contrapresentes oferecidos levam em conta a diferença dos sexos. Às vezes, só há meninas: na casa da Marianne, todas ganharam anéis de meninas. Em compensação, na casa do Tom, os contrapresentes foram ganhos numa pescaria: eram farces et attrapes, ${ }^{*}$ consideradas unissex; mesma coisa na casa do Pierre, todas as crianças saíram com um títere, ou na do Vincent, com uma bolsa de piratas contendo moedas de ouro em chocolate. No aniversário de Manon, em compensação, os contrapresentes eram nominativos, e variavam em função do sexo e dos gostos, conhecidos ou supostos, de cada uma das crianças.

- Os contrapresentes são geralmente acompanhados por balas. Não somente, segundo a regra da glutonaria (Sirota, 1997), as crianças ingurgitam tantas balas quantas querem durante todo $\mathrm{o}$ aniversário, mas o objeto que faz às vezes de contrapresente também é acompanhado por uma pequena quantidade de doces destinados a serem degustados mais tarde. As balas são mesmo as moedas dos pequeninos.

- Os contrapresentes devem satisfazer as crianças presentes, segundo uma regra de felicidade da infância desabrochada (idem, ibid.). Por isso, uma bolsa de troca costuma ser improvisada, por iniciativa das crianças ou da mãe: as crianças vão trocando até obterem o objeto de seu desejo. A tal ponto que, às vezes, diante da

N. do T.: Literalmente, "brincadeiras/truques e pegadinhas", trata-se de uma vasta gama de artigos, que vai de brinquedinhos até disfarces, muito populares na França. 
decepção de algumas crianças, as mães surgem com novos objetos para satisfazer o "irredutível ranzinza", pois, em hipótese alguma, uma criança pode ir embora do aniversário chorando.

Como as crianças assistem a um número não desprezível de aniversários, não é fácil renovar o estoque de presentes, motivo pelo qual as mães hão de fazer mostra de uma certa engenhosidade.

\section{A fabricação dos contrapresentes ou a inventividade das mães}

Que objetos se tornam contrapresentes? A lista varia e resulta de diferentes estratégias que podem ser associadas, com os anos, segundo o orçamento ou a disponibilidade das mães:

- A estratégia da pronta entrega: objetos do comércio vendidos praticamente como tais em lojas de brinquedos ou supermercados, na seção "aniversários" (baralhos de mistigri e sept familles; carrinhos, aviōes miniatura, falsos óculos, aparelhos de fazer bolhas de sabão, geleinha, kits de pinturas, miniportas-moeda etc.). Não são muito caros e são vendidos em pacotes, o que subentende uma distribuição coletiva.

- A estratégia da coleta, que envolve objetos comprados, coletados ou encontrados para este uso ao longo do ano, ou algum tempo antes, pelas mães, pois são basicamente elas que se preocupam com o fornecimento de pequenos contrapresentes. As fontes de abastecimento diversificam-se, não se trata mais apenas das seções especializadas dos supermercados ou de lojas de brinquedos, mas também das lojas de soldos, Monoprix, lojas de presentes. Podem ser títeres, agendas ou porta-moedas, quadrinhos para pintar, espadas, cordas de pular, lápis com cabeças de animais ou conjuntos heteróclitos, embora de mesmo valor comercial, massinha fluorescente, chaveiros, lápis-lupas. Às vezes, miniaturas dos verdadeiros presentes são utilizadas como contrapresentes: miniPower Rangers, minipersonagens de Tintim, minicaixinhas da Lego ou da Playmobil.

- A estratégia dos "brechós de pacotilha": mais rebuscados, certos contrapresentes são o resultado de um verdadeiro trabalho de busca de mães que procuram "pequenos objetos para renovar o gênero, sem sair de uma faixa de preços aceitáveis, pois, geralmente, trata-se de oferecer entre 5 e 20 presentes, sem dar sempre os mesmos". Uma mãe, habituée do Marché aux Puces "encontrou” um estoque de velhos anéis, outra, um conjunto de braceletes brasileiros, outra ainda compra garrafinhas que, com um lindo embrulho, tornam-se presentes. Uma outra ainda trouxe uma série de pequenas cerâmicas de suas férias na Tunísia, e um conjunto de colares para o aniversário de suas duas filhas; outra ainda, espelhinhos decorados, de sua viagem familiar na América Latina.

- A estratégia da fabricação: às vezes esses objetos são até fabricados especialmente em função do tema do aniversário; trata-se, então, principalmente de mães que não trabalham fora e confeccionam: foguetes caseiros, lunetas de pirata, bolsas de moedas de ouro em chocolate para um aniversário pirata; quadros de guerreiro índio com uma foto cola- 
da num suporte de papelão pintado, para um aniversário com tema de índio; ou personagens em massa de sal. Às vezes, esses objetos são confeccionados durante o aniversário pelas próprias crianças durante atividades-oficinas (máscaras pintadas, broches de espuma, ou em Magie Plastik).

- A estratégia do desvio é outra fonte de renovação e inspiração: objetos usuais desviados em presentes tais como lápis ou canetas hidrográficas (do tipo "volta às aulas") comprados num Monoprix: "Pois estava cansada de oferecer porcarias", oveiros nos quais está inscrito o nome de cada criança com caneta hidrográfica, livros ou cadernos de colorir.

A cena da generosidade pode até existir literalmente: quando do aniversário da Marion, sua mãe usou uma bomba, isto é, um tubo de papelão que explodiu depois de acender seu estopim, lançando no ar muitas serpentinas, balas e brinquedinhos. Todas as crianças se jogaram então no chão para apanhar o máximo que pudiam, reproduzindo a cena antiga comentada por Starobinski (1994), a propósito do nono devaneio do caminhante solitário de J.-J. Rousseau. O aniversariante também participa, e, em geral, não é o que menos aproveita da inversão das regras habituais de acesso aos doces.

Por que tanta engenhosidade e pesquisa para esses "objetos pequenininhos"? Trata-se, às vezes, de estratégias de distinção: fazer melhor que os outros, fazer diferente; outras vezes, de princípio educativo, de raciocínio estético, de princípio financeiro ou de prazer, pois encontrar esses contrapresentes representa uma parte não desprezível dessa provação da "parentalização" (Winnicott, 1969) que o aniversário representa. Nisso se conjugam aspecto financeiro, em razão do número de objetos que se deve prover, encenação representativa da família, com uso interno e externo, e princípio de prazer, uma vez que os objetos devem ser oferecidos e agradar às crianças. As mesmas coisas "mais baratas" que os presentes estão em jogo e vão se combinar na escolha desses contrapresentes.

Se contarmos uns dez convidados, em média, por aniversário, durante uns dez aniversários até os 10 anos aproximadamente, uns 100 contrapresentes são comprados por criança, o que, para uma mãe, pode significar comprar 100, 200 ou 300 presentes durante sua "carreira" de mãe. E em sentido contrário, para uma criança convidada a uma centena de aniversários, uma centena de contrapresentes são recebidos nessas ocasiões.

Portanto, o peso financeiro não é desprezível e as mães costumam afirmar que se dão um limite de 10 a $20 \mathrm{~F}$ por presente, o que equivale a 
um orçamento de 100 a 400 F. Contudo, durante a entrevista, elas explicam que, geralmente, acabam "não resistindo" e escolhem objetos de um valor superior. Por sinal, se acrescentarmos os preços das balas e do embrulho dos contrapresentes, a média costuma se aproximar muito mais dos $30 \mathrm{~F}$, a multiplicar pelo número de convidados.

\section{O "potlatch" da infância}

Por meio dos presentes de aniversário desenha-se e instaura-se um verdadeiro sistema de troca que abarca um valor monetário elevado.

Embora a dimensão da ameaça de destruição eventual, por meio do jogo do sobrelanço, não esteja presente, pode-se qualificar, por analogia, o modo de funcionamento deste círculo de troca infantil de "potlatch" da infância, pois o que está mesmo em jogo, nele, é o lugar de cada um e seu pertencimento ao círculo. Isso envolve um investimento monetário certo. Em média, quando de um aniversário "amigal”, uma criança recebe uns dez presentes de seus convidados, cujo valor monetário médio é de $80 \mathrm{~F}$, com somas que variam entre 40 e $150 \mathrm{~F}$. Ou seja, dez presentes a $80 \mathrm{~F}$ dão $800 \mathrm{~F}$. Ela mesma oferece dez contrapresentes com um valor médio de $30 \mathrm{~F}$, equivalentes a um gasto de $300 \mathrm{~F}$. Depois desse convite, ela mesma será convidada por uns dez colegas, essencialmente, embora não necessariamente, os mesmos e, portanto, vai oferecer, por sua vez, uns dez presentes com valores provavelmente equivalentes. Este conjunto de presentes oferecidos vai se construir em torno de um valor médio geralmente idêntico e, portanto, um total equivalente a $800 \mathrm{~F}$ será gasto para participar do "potlatch". A criança receberá então uns dez contrapresentes semelhantes àqueles que ela mesma ofereceu.

Assim, cada criança recebe uns dez presentes e uns dez contrapresentes, e oferece uns dez presentes e uns dez contrapresentes para fazer parte do círculo. A troca econômica, portanto, é de $1.100 \mathrm{~F}$, em média, para cada par do círculo (esquema a seguir) durante um ano. Multiplicados pelo número de pares, ou seja, dez no nosso exemplo, chegamos ao seguinte resultado: um "potlatch" tem um funcionamento anual que gira em torno dos $11.000 \mathrm{~F}$. Esse círculo se estabeleceu e funciona a pleno vapor, nesse nível financeiro, entre os 4 e os 11 anos e, portanto, ocorre em torno de oito vezes por criança. O que significa, para cada família, um gasto de $1.100 \mathrm{~F}$ em presentes multiplicado por oito, ou seja, globalmente, um investimento de $8.800 \mathrm{~F}$ em presentes por criança para 
manter esse rito de sociabilidade. Como "é preciso tempo para executar toda contraprestação” (Mauss, 1950, p. 194 e ss.), o rito precisa de um certo número de anos para se estabelecer, uma vez que, por definição, ele pode apenas ocorrer uma vez por ano e em data fixa, para cada criança. Logo, no percurso de sua órbita, durante esses oito anos, o ciclo totaliza trocas econômicas de um valor de $88.000 \mathrm{~F}$.

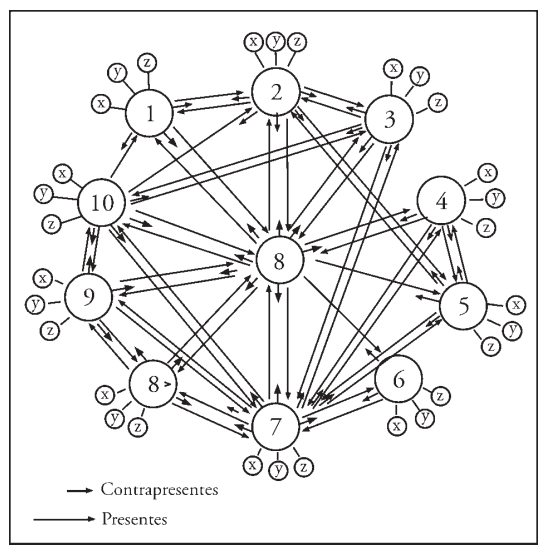

A estrutura da troca em torno do "potlatch" dos presentes de aniversário.

Entretanto, essa soma não resume o custo financeiro do aniversário, pois a realização do rito, por meio da recepção mundana que enseja, requer outras despesas. Neste estágio da análise, podemos nos perguntar se o investimento financeiro nesse "potlatch" não é eliminatório para algumas famílias, embora poucas tenham consciência da massa financeira total realmente em jogo. Todavia, algumas acrescentam outras despesas ligadas a aspectos ostensivos tais como oferecerem espetáculos de mágicos ou de palhaços. ${ }^{11}$ Há também oferta de comida durante a festa de aniversário que sempre inclui, pelo menos, um bolo, bebidas doces e balas, e a instalação de um cenário específico para a oportunidade. Ainda é preciso acrescentar a essa troca econômica os presentes familiares, isto é, os dos pais, avôs, padrinhos, madrinhas, tios e tias, que, por sua vez, ocorrem com nenhuma ou relativamente pouca reciprocidade (principalmente com primos e primas da mesma faixa etária ou afilhados). Pois o aniversário "amigal" subentende o aniversário familiar que ocorre em outro momento segundo um protocolo em parte idêntico, em parte diferente, mas que também inclui presentes cujos valores são nitidamente superiores aos dos presentes oferecidos pelos amigos. 
Mais tarde, esse rito evolui e assume formas diferentes para manter o vínculo social no grupo de pares e instaurar as normas da adolescência.

\section{Da infância à adolescência, da constituição da identidade à celebração da identidade}

Aos poucos, os jovens tornam-se parcialmente autônomos, o aniversário vai deixando de depender dos pais, e a compra e a escolha do presente ocorrem no universo do grupo de pares, exceto no que diz respeito ao dinheiro, a não ser quando a mesada basta. $\mathrm{O}$ lugar na rede social marcase diferentemente, segundo um código muito preciso, e os presentes são ao mesmo tempo mais individualizados e construídos coletivamente, e é preciso então concordar quanto à escolha do presente. Se as contribuiçôes de cada um são inferiores, o princípio de um presente coletivo permite juntar a soma necessária, a qual pode ser elevada. Laetitia sonhava com Doc Marten's ${ }^{12}$ que seus pais não queriam lhe comprar; por iniciativa de sua melhor amiga, todos os amigos se juntaram para fazer uma vaquinha e oferecer-lhe um par para seus 13 anos. Do mesmo modo, para seus 16 anos, Rachel recebeu um casaco de couro, comprado num brechó por seis amigas, cada uma contribuindo com $50 \mathrm{~F}$. Caso essa contribuição não acabe com os fundos disponíveis, a especificidade de cada uma das relaçôes será significada por meio de um presente pessoal que vem se acrescentar ao coletivo: "É uma oportunidade para comprar presentinhos engraçados: uma caneta vermelha que ela sempre pede emprestada, uma rosca com uma vela em cima". Nesse caso, o aspeto monetário não é essencial: "Ela lhe deu um cartaz de que gostara quando foi na casa dela, e que tirou para mudar a decoração de seu quarto" (Laetitia). Os presentes seguem a regra da surpresa e da "desejabilidade", e costumam ser objetos simbólicos muito prezados pela faixa etária, por exemplo um cartaz do seriado "Friends". Em contrapartida, Axel escreveu um poema em alexandrinos para o aniversário de Rachel: "Ele estava duro e tinha outro presente para comprar naquela semana, de que tinha preferência".

$\mathrm{Na}$ adolescência, a multiplicação dos aniversários a se festejar pode virar um problema. Assim, da agenda escolar ${ }^{13}$ de Johanna, que está na terceira série do ensino médio, constam 44 aniversários (entre amigos e família). Sem saber, ela retoma com isso as prescrições dos manuais de civilidade contemporâneos, tais como o de Nadine de Rotschild, citado por Picard (1995), que aconselha anotar na agenda, no começo do ano, os aniversários de que se deve lembrar. Seu orça- 
mento nunca bastaria. Por isso, ela distingue três círculos que hierarquizam os graus de relações e intimidade que mantém: no último círculo, os que ela conhece pouco, ou não o suficiente, a quem ela deseja um feliz aniversário por telefone ou por uma palavra gentil de manhã, na sala de aula; em seguida vem o segundo círculo, dos colegas para os quais ela participa da vaquinha com 10 a $30 \mathrm{~F}$; e finalmente, no primeiro círculo, os amigos a cujas casas ela é geralmente convidada ou aqueles para quem ela organiza o aniversário e oferece um presente que pode chegar a $150 \mathrm{~F}$. Assim, ela organizou o aniversário do Benjamin, seu melhor amigo: "Marcamos um encontro no McDonald's e aí, surpresa, a gente estava em dez, mais ou menos, e fomos todos num Dame Tartine, e pagamos a parte dele. A gente tirou um monte de fotos que lhe oferecemos num caderno, e eu lhe dei a fita que gravei" (Johanna).

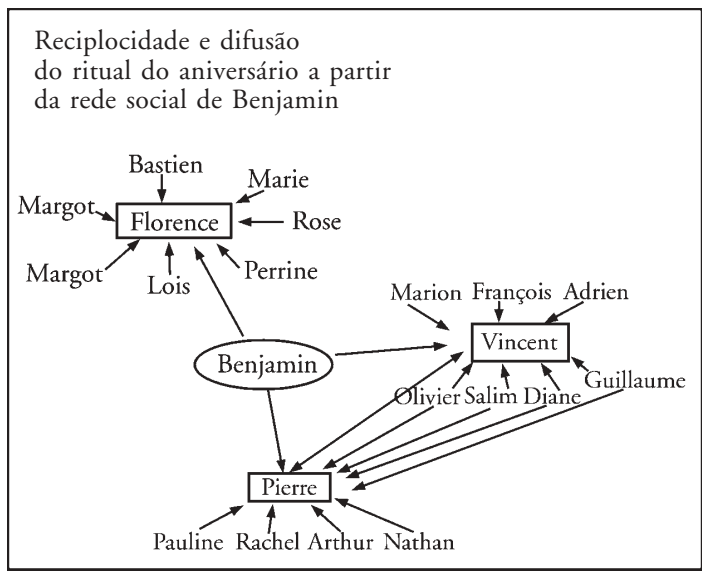

Gráfico de troca de presentes de aniversário em torno de Benjamin a partir dos troféus de Florence, Pierre e Vincent, listados no quadro às p. 543-544

Cabe acrescentar que, com freqüência, naquela idade, a festa é organizada pelos amigos, cada etapa do preparo representando um presente em si. Rachel ficou muito nervosa, nenhum amigo parecia livre

* N. do T.: Rede de restaurantes que servem pratos de comida "não-convencional" acompanhados por fatias de pão grelhado no azeite (tartines), com preços variando entre 100 e $300 \mathrm{~F}$, aproximadamente. 
naquele sábado à noite; uma amiga sacrificou-se e marcou um encontro, as outras embaralharam-se nas suas mentiras e pretextos, e acabaram solicitando a ajuda de seus pais para mantê-la ocupada naquela tarde, pois haviam de preparar a noite discretamente, o que nem sempre corre sem percalços:

"Cyril se encarregou de fazer o bolo, mas não deu certo, ficou uma massa grossa de brownie no fundo da forma que não tinha cozinhado, só deu zica, metade caiu na meia-calça da mãe dele. Teve velas, e a gente só conseguiu comer um pouco daquele chocolate fazendo panquecas, nas quais a gente botava um pouquinho daquela espécie de massa grossa”. (Myriam)

Os presentes materializam-se também pela compra de bebidas e de ingredientes, a confecção de panquecas, ou o empréstimo do local, com a negociação, a responsabilidade e a faxina que isto supõe. "Cécile considerou que foi seu presente, foi na casa dela. Ela precisou ver se o estúdio ia estar vazio, ela perguntou a seus meio-irmãos, e se envolveu mais nisso, e também comprou a comida" (Aïdée). A ambigüidade da autonomia dos jovens surge claramente, quando a noite ainda é organizada e preparada pelos pais, quer seja um bufê ou uma macarronada, pois estes são convidados a desaparecer prontamente assim que a festa começar.

\section{A festa de aniversário, um presente em si}

Podemos nos limitar a uma análise simbólica ou financeira das trocas materiais? É claro que, para as crianças, os preparativos e a própria festa de aniversário têm valor de obrigação e até mesmo de naturalidade, independentemente de elas serem pequenas ou grandes. Mas, para quem a organiza, ela tem valor de presente, como os pais, por exemplo, entre os quais alguns a percebem como uma verdadeira provação. Eles têm o sentimento de oferecer lembranças de infância que fabricam para seus próprios filhos (embora sejam muito lúcidos quanto a eventuais acertos de conta ou aos efeitos paliativos com relação a sua própria infância). Temos aqui a construção voluntária de um imaginário da infância desabrochada, resultante em parte da vulgarização da psicanálise e dos trabalhos sobre a psicologia da criança, junto às classes médias. Do mesmo modo, no que concerne aos amigos, há uma fabricação da representação de uma amizade ideal pelo ajuntamento e pela exposição do grupo de pares. ${ }^{14}$ Portanto, trata-se de uma construção social que nunca é evidente, garan- 
tida, nem bem-sucedida de antemão. Daí esse reino da surpresa ou da meia-surpresa que reencontramos mais tarde nos aniversários de adultos. Estes atualizam, em diferentes etapas da vida, o conjunto da rede social.

Se, no âmbito de uma economia de dádiva, considerarmos o conjunto do que se oferece como presente, perceberemos muito rapidamente que a primeira definição que se limita à ordem do material não basta, pois, para os próprios atores, a situação do aniversário pode ser considerada um presente em si. A análise apresentada aqui aborda apenas os presentes e não a própria organização da festa de aniversário. Ora, durante esta, espetáculos e jogos são freqüentemente propostos, o que representa um esforço bastante pesado para certos pais que consideram toda essa organização um verdadeiro presente, com um peso financeiro certo. $\mathrm{O}$ mesmo vale em caso de convites específicos ${ }^{15}$ para essa ocasião, como num restaurante, num Aquaboulevard, ${ }^{16}$ no teatro, numa reunião de atletismo ou num show de um grupo de cantores de moda, das Spice Girls, por exemplo.

Entretanto, independentemente da materialidade e das formas assumidas, trata-se mesmo, por meio desses presentes, de criar dispositivos destinados a manter o vínculo social. Portanto, eles não têm apenas valor de uso e valor de troca, mas também valor de vínculo. Como bem lembram Godbout \& Caillé (1992, p. 20):

Mauss parece ter tido dificuldades em reconhecer que a dádiva não existe apenas, hoje em dia, como uma espécie de sobrevivência, ilustrada pelo exemplo, afinal marginal, dos presentes de aniversário ou de ano-novo. (...) Do mesmo modo, para esclarecer o conceito de reciprocidade, Claude Lévi-Strauss descreve a prática da troca de garrafas de vinho em pequenos restaurantes do sul da França. O exemplo claro é simpático e eloqüente, mas se a dádiva se manifestasse apenas sob esses aspectos menores e marginais, não haveria muito o que se preocupar com ela, exceto por nostalgia ou gosto pelos estudos folclóricos.

Essa longa descrição etnográfica do uso desses pequenos objetos que são os presentes de aniversário fez surgir o que está em jogo na relação social que se constrói por meio das formas contemporâneas da dádiva, mais especificamente no ritual do aniversário. Assim, por meio do jogo dos presentes de aniversário, pode-se ler a versão moderna de um modo clássico de fabricação do vínculo social e, mais especificamente, o modo de constituição de uma cultura da infância. O percurso do presente revela o trabalho de construção da identidade social ao longo do ciclo, tan- 
to no momento da escolha como no da oferta, ou da avaliação do troféu. Por meio das múltiplas interaçôes da vida cotidiana instauram-se assim o ritual do aniversário e a "profissão" de criança. A abordagem etnográfica permite apreender o papel de cada ator social na construção desse ritual, pois o presente está no cerne de um verdadeiro trabalho de negociação no qual se confrontam incessantemente normas e valores. Não se trata apenas de uma negociação no sentido de um estilo educativo refletindo a evolução das concepções educativas contemporâneas, mas de uma posição teórica que atribui um lugar na qualidade de ator à criança e permite revelar o trabalho social que lhe é próprio. A parentalização constrói-se paralelamente à socialização da criança. A dinâmica da evolução das sociabilidades infantis e das regras de civilidade apenas pode ser entendida aqui se restituirmos à criança seu lugar como ator social.

Resta, entretanto, apreender qual a parte da autonomia e a da dependência da criança nessa construção perante o conjunto dos atores em jogo, quer se trate das diversas instâncias de socialização ou da sociedade comercial.

\section{Recebido em dezembro de 2004 e aprovado em abril de 2005.}

\section{Notas}

1. Actes Sud, Coll. Les petits bonheurs. Assim como as estrofes do "Ha-vamàl", velho poema escandinavo que Mauss usou como epígrafe da introdução de seu Ensaio sobre a dádiva, essa poesia se destina a "pôr diretamente o leitor na atmosfera de idéias e de fatos na qual vai se mover nossa demonstração" (1950, p. 145).

2. Este artigo se inscreve num programa de trabalho sobre a constituição de uma sociologia da infância (Sirota, 1994, 1998) e mais exatamente de uma pesquisa sobre o aniversário como ritual de socialização e encenação representativa da infância contemporânea. Por isso, os presentes serão considerados aqui os analisadores deste processo.

3. Ao utilizar o termo "regra", referimo-nos aqui, por um lado, à noção de regra de civilidade (Érasme, 1992) e, por outro, à análise de T. Caplow (1986) que ressalta as regras relativas aos presentes de Natal, uma publicação anterior a respeito desta pesquisa tendo enunciado um certo número de regras do aniversário (Sirota, 1997).

4. O termo retoma a expressão de uma criança para denominar o aniversário que reúne os amigos. Resta uma pergunta: trata-se da criação ou da difusão de um ritual existindo principalmente em certas classes sociais? De fato, esse ritual parece provir da aristocracia inglesa (o que diários ingleses parecem comprovar, com seus anúncios de mágicos propondo seus serviços para festas de aniversário). Sobre sua difusão, ver "L'anniversaire, un exemple de manuel de civilité de l'enfance moderne", a ser publicado em Sociétés et cultures enfantines, actes du colloque de la Société d'Ethnologie française, Lille, Presses du Septentrion, 1999. 
5. Esta pesquisa foi desenvolvida a partir de uma "caça" etnográfica num bairro parisiense, o $13^{\circ}$ arrondissement. Desenvolvida num modo particular, uma vez que me torno etnóloga de minha própria tribo, observo os aniversários aos quais meus próprios filhos são convidados, o que me permite entrar na vida privada em meio urbano pela via da observação. A amostra inclui uns 50 aniversários, principalmente organizados nas famílias de classe média. A pesquisa constrói-se na base da observação direta, umas reportagens fotográficas ou vídeo sendo empregados como diário de campo, seguidos por entrevistas.

6. Os preços mencionados são em francos franceses, pois a moeda utilizada durante a pesquisa de campo na França era o franco (um franco era igual a aproximadamente $\mathrm{R} \$ 0,60$ ).

7. Loja que vende artigos baratos.

8. De fato, estatisticamente, esta é a segunda maior oportunidade de compras de brinquedos, após o Natal, oportunidade não desperdiçada pela indústria comercial do brinquedo, por exemplo, que vê nela uma possibilidade de sair de um mercado sazonal demais para seu gosto e de assim aumentar suas vendas (Herpin \& Verger, 1996).

9. J.-P. Albert (1993) relatava que $80 \%$ das moças têm ou tiveram um diário, 56\% têm papel de cartas, e o historiador P. Lejeune (1990) notava que, hoje em dia, 75\% da correspondência é feminina.

10. Segundo a expressão de uma criança.

11. É preciso ser muito cauteloso a respeito dos sistemas de interpretação das despesas ocasionadas pelos aniversários, pois um aniversário organizado fora pode sair muito menos caro, tanto em investimento de tempo como de dinheiro, para os pais, ou paliar condições de habitação que tornam difícil convidar os amigos. Em contrapartida, a hierarquia dos valores depende do estilo educativo das famílias: para algumas, é o investimento em tempo que marca o prêmio concedido à criança, para outras, será o investimento financeiro.

12. Sapatos muito em voga entre os "teenagers".

13. Quando do ingresso no colégio, a agenda marca a autonomia da criança e simboliza a mudança de categoria de idade. Ela se torna o confidente dos jovens, o que gera um grande descontentamento entre os professores, que, às vezes, contestam fortemente esse desvio de função, no qual se pode ler a vida infanto-juvenil.

14. As pesquisas quantitativas de campo sobre sociabilidade realizadas pelo INSEE (equivalente francês do IBGE) avaliam o número médio de amigos na turma, na adolescência, em cerca de cinco (Herpin, 1996).

15. Não trataremos aqui dos aniversários integralmente organizados em redes de restaurantes como McDonald's, que propõem uma prestação especial para essa ocasião, pois a "terceirização" desse ritual póe muito mais coisas em jogo.

16. Parque aquático com várias atrações.

\title{
Referências bibliográficas
}

\author{
ALBERT, J.-P. Les écritures domestiques. In: FABRE, D. (Dir.). Les écritures \\ ordinaires. Paris: Centre Georges Pompidou; POL, 1993.
}

BEAUVOIR, S. de. Le deuxième sexe. Paris: Gallimard, 1949. 
BELLOTI, E.G. Du côté des petites filles. Paris: Éd. des Femmes, 1973. BROUGÈrE, G. Rites de Noël et don du jouet. Dialogue, n. 110, déc. 1990.

CAPLOW, T. Les cadeaux de Noël à Middietown ou: comment faire respecter une règle sans pression apparent. Dialogue, n. 91, p. 43-61, jan./ mar. 1986.

DETTES et cadeaux dans la famille. Dialogue, n. 110, déc. 1990.

ELIAS, N. La civilisation des mours. Paris: Calmann-Lévy, 1973.

ÉRASME. La civilité puérile. In: SEguin, J.-P. (Ed.). La bienséance, la civilité et la politesse enseignée aux enfants. Paris: Le Cri; Bruxelles: JeanMichel Place, 1992.

FABRE, D. (Dir.). Écritures ordinaires. Paris: Centre Georges Pompidou; POL, 1993.

FALCONNET, G.; LEFAUCHEUR, N. La fabrication des mâles. Paris: Seuil, 1975.

GODBOUT, J.T.; CAILLÉ, A. L'esprit du don. Paris: La découverte, 1992.

HERPIN, N. Les amis de classe: du collège au lycée. Économie et Statistique, Paris, n. 293, 1996.

HERPIN, N.; VERGER, D. Cadeaux de fin d'année, fête de l'enfance ou de la famille? INSEE Première, n. 426, 1996.

JAMES, A.; PROUT, A. Constructing and reconstructing childhood. London: Falmer, 1997.

LEJEUNE, P. “Chers cahiers”, témoignages sur lê journal personnel. Paris: Gallimard, 1990.

MAUSS, M. Essai sur le don. In: MAuss, M. Sociologie et anthropologie. Paris: PUF, 1950. p. 145-279.

MONTANDON, C. L'éducation du point de vue des enfants. Paris: L'Harmattan, 1997.

PICARD, D. Les rituels du savoir-vivre. Paris: Seuil, 1995. 
REVEL, J. Les civilités de l'âge moderne. In: Revel, J. Politesse ou sincérité. Paris: Esprit, 1994.

SINGLY, F. Les jeunes et la lecture. Paris: Ministères de l'Education Nationale et de la Culture, 1993. (Dossiers, éducation et formations, n. 24)

SIROTA, R. L'enfant dans la sociologie de l'éducation, un fantôme ressuscité? Revue de l'Institut de Sociologie, n. 1-2, 1994.

SIROTA, R. Anniversaire familial, anniversaire copinal, anniversaire scolaire. In: Hardy, M.; Bouchard, Y.; Fortier, G. (Dir.). L'école et les changements sociaux: défi à la sociologie. Montréal: Logiques, 1997.

SIROTA, R. L'émergence d'une sociologie de l'enfance: évolution de l'objet, évolution du regard. Éducation et Sociétés, n. 2, 1998.

SIROTA, R. Emergência de uma sociologia da infância: evolução do objeto e do olhar. Cadernos de Pesquisa, São Paulo, n. 112, p. 7-31, mar. 2001.

SIROTA, R. As civilidades da infância contemporânea:o aniversário ou a decodificação de uma configuração. Fórum sociológico "Cores da Infância: realidades fragmentadas”, n. 34, p. 49-70, 2000/2001.

SIROTA, R. When the birthday invitation knocks again and again on the door: learning and construction of manners. Zeitschrit fûr Qualitative Bildungs-Beratung und Socialforschung, n. 1, p. 11-39, 2002.

SIROTA, R. Le gâteau d'anniversaire, de la célébration de l'enfant à son inscription sociale; La lettre de l'enfance et de l'adolescence. Revue $d u$ Grape, ERES, n. 35, p. 51-65, 2004.

STAROBINSKI, J. Largesse: catalogue d'exposition. Paris: RMN, 1994.

WINNICOTT D. W. De la pédiatrie à la psychanalyse. Paris: Payot, 1969.

ZONABEND, F. La mémoire longue. Paris: PUF, 1980. 